\title{
Cancer testis antigens expression in mesothelioma: role of DNA methylation and bioimmunotherapeutic implications
}

\section{Sigalotti', S Coral', M Altomonte', L Natali', G Gaudino², P Cacciotti' ${ }^{2}$ R Libener ${ }^{3}$, F Colizzi', G Vianale', F Martini ${ }^{5}, M_{\text {Tognon }}^{5}$, A Jungbluth ${ }^{6}$, J Cebon ${ }^{7}$, E Maraskovsky ${ }^{7}, L_{\text {Mutti }}^{8}$ and M Maio*,I}

'Cancer Bioimmunotherapy Unit, Centro di Riferimento Oncologico, IRCCS, 3308 I Aviano, Italy; 'University of Piemonte Orientale 'A. Avogadro' Department of Medical Sciences, 28100 Novara, Italy; ${ }^{3}$ Azienda Ospedaliera 'SS Antonio e Biagio', 15100 Alessandria, Italy; ' University 'G D'Annunzio', Department of Oncology and Neuroscience, 66100 Chieti, Italy; ${ }^{5}$ University of Ferrara, Department of Morphology and Embryology, 44100 Ferrara, Italy; ${ }^{6}$ Ludwig Institute for Cancer Research, Memorial Sloan-Kettering Cancer Center, 1275 York Avenue, New York, NY I002I, USA; ' Ludwig Institute for Cancer Research, Austin and Repatriation Medical Centre, Heidelberg, Victoria 3084, Australia; ${ }^{8}$ Health Authority II Piemonte, Laboratory of Clinical Oncology and IRCCS 'S Maugeri' Foundation, 27100 Pavia, Italy

Recent evidences suggest that malignant mesothelioma may be sensitive to immunotherapy; however, little is known about malignant mesothelioma-associated tumour antigens. Focusing on cancer/testis antigens, the expression of well-characterised immunogenic tumour-associated antigens was investigated in malignant mesothelioma cells. At variance with MAGE-4 and NYESO- I, malignant mesothelioma cells frequently expressed MAGE-I, -2 and -3, GAGE I-2, GAGE I-6, SSX-2 and SSX I-5, and distinct malignant mesothelioma cells concomitantly expressed at least four cancer/testis antigens. Additionally, the tumour-associated antigens RAGE-I was expressed at high levels in both benign and malignant mesothelial cells. Lastly, treatment with the DNA hypomethylating agent 5-aza-2'-deoxycytidine induced and up-regulated the expression of the cancer/testis antigen examined in malignant mesothelioma cells. Overall, these findings strongly suggest that cancer/testis antigens-based immunotherapy may represent a suitable therapeutic approach to malignant mesothelioma, and foresee the clinical use of 5-aza-2'-deoxycytidine to design new chemo-immunotherapeutic strategies in malignant mesothelioma patients. British Journal of Cancer (2002) 86, 979-982. DOI: 10.1038/sj/bjc/6600I74 www.bjcancer.com

(c) 2002 Cancer Research UK

Keywords: mesothelioma; immunotherapy; 5-aza-2'-deoxycytidine; cancer testis antigens; methylation

No conventional therapy prolongs survival of malignant mesothelioma (MM) patients (Lee et al, 2000); however, immunotherapy may have a positive impact in the treatment of MM. In fact, MM cells can present recall antigens to the immune system (Mutti et al, 1998), and systemic administration of IL-12 generated immune responses to MM in murine models (Caminschi et al, 1998). Additionally, tumour-reactive antibodies were detected in sera of MM patients (Robinson et al, 1998), and non-specific immunotherapy showed some clinical efficacy in human MM (Castagneto et al, 2001). Despite these evidences, little is known about MM-associated tumour antigens that may represent useful therapeutic targets to implement immunotherapeutic approaches in MM patients.

Among known immunogenic tumour-associated antigens (TAA) (for review see Traversari, 1999), cancer testis antigens (CTA) including MAGE, GAGE and SSX gene families, and NY-ESO-1, are expressed in solid tumours of different histotype but not in normal tissues except testis (Traversari, 1999). Due to their unique tissue distribution, and recognition by cytotoxic $\mathrm{T}$ lymphocytes (CTL) and/or by B lymphocytes, CTA represent useful therapeutic targets in solid malignancies (Traversari, 1999).

To extend to MM patients CTA-based immunotherapeutic approaches that are proving promising in solid tumours (Marc-

*Correspondence: M Maio; E-mail: mmaio@cro.it Received 29 August 200I; revised 18 December 200I; accepted 7 January 2002 hand et al, 1999; Nishiyama et al, 2001), we analysed the expression of well-characterised CTA by mesothelial and MM cells.

Furthermore, due to the demonstrated role of DNA methylation in regulating gene expression (Jones and Takai, 2001), and since promoter methylation is involved in the expression of MAGE genes in human melanoma (De Smet et al, 1996, 1999; Sigalotti et al, 2002), we investigated the role of the DNA hypomethylating agent 5-aza-2'-deoxycytidine (5-AZA-CdR) in regulating the differential distribution of CTA and their constitutive levels of expression in MM.

Our results provide the first evidence that different CTA can be co-expressed in and among MM specimens, and also highlight that DNA methylation accounts for their heterogeneous distribution in individual MM tissues.

\section{MATERIALS AND METHODS}

\section{Mesothelial and mesothelioma cells and 5-AZA-CdR treatment}

Primary and long-term cultures of MM cells from pleural effusion of MM patients, and cultures of mesothelial cells from pleural effusion of patients with heart failure were obtained and grown as previously described (Mutti et al, 1998). Primary cultures were utilised between the second and third passage in vitro. Treatment with 5-AZA-CdR (Sigma Chemical Co., St. Louis, MO, USA) was performed as described (Coral et al, 1999). 
Monoclonal antibodies, antisera, reagents and biochemical assays

The anti-NY-ESO-1 mAb ES121 has been previously described (Jungbluth et al, 2001). The anti-NY-ESO-1 rabbit antiserum was obtained from 20-week-old NZW female rabbit immunised at weekly intervals with subcutaneous injections of $1 \mathrm{mg}$ of recombinant NY-ESO-1 protein. Immunoprecipitation, SDS-PAGE, and Western blotting were performed as described (Maio et al, 1991).

\section{Reverse transcription (RT) polymerase chain reaction (PCR) analysis and competitive PCR}

Total RNA extraction and RT-PCR reactions were performed as described (Coral et al, 1999). Oligonucleotide primer sequences and gene-specific PCR amplification programs utilised have been defined for MAGE-1, -2, -3, -4 (Brasseur et al, 1995), NY-ESO-1 (Jäger et al, 1998), GAGE 1-2 (Van den Eynde et al, 1995), GAGE 1-6 (Van den Eynde et al, 1995), SSX 1-5 (dos Santos et al, 2000), SSX-2 (Sahin et al, 2000), RAGE-1 (Neumann et al, 1998), tyrosinase and Melan-A/MART-1 (van Elsas et al, 1996). The integrity of each RNA and oligo-dT-synthesised cDNA sample was confirmed by the amplification of the $\beta$-actin housekeeping gene (Coral et al, 1999). Ten $\mu \mathrm{l}$ of each RT-PCR sample were run on a $2 \%$ agarose gel and visualised by ethidium bromide staining.

The level of expression of distinct antigens was scored according to the intensity of the specific RT-PCR product, which was obtained by densitometric analysis of ethidium bromide-stained agarose gels using a Gel Doc 2000 documentation system and the QuantityOne densitometric analysis software (Bio-Rad, Milan, Italy). The intensity of RT-PCR products were compared to that of the reference human melanoma cell line Mel 142 (MAGE-1-, -2-, -3-, -4-, GAGE 1-2-, GAGE 1-6-, SSX-2- and SSX 1-5-positive) or human fibrosarcoma cell line HT1080 (NY-ESO-1-positive) or human renal cell carcinoma cell line LE9211 (RAGE-1-positive). Samples were scored -, no RT-PCR product detectable; +, expression level $<10 \%$ to that of the appropriate reference cell line; ++ , expression level $>10 \%$ to that of the appropriate reference cell line. Competitive PCR for MAGE-3 and $\beta$-actin was performed as described (Sigalotti et al, 2002).

\section{RESULTS}

\section{CTA expression in mesothelial and MM cells}

Three primary cultures (MES-CM98, MES-MM98, and MESOC99) and three long-term cultures (MPP-89, MES-1, and MES2) of MM cells were analysed for their constitutive expression of
MAGE-1, -2, -3, -4, NY-ESO-1, GAGE 1-2, GAGE 1-6, SSX-2, and SSX 1-5. RT-PCR analysis revealed frequent expression of CTA belonging to the MAGE, GAGE and SSX gene families; in contrast, a reduced frequency of MAGE-4, and NY-ESO-1 was found (Table 1). None of the CTA examined were detected in mesothelial cells (Table 1).

Noteworthy, four out of six MM cells investigated expressed the TAA RAGE-1 (Table 1), and its expression was also detected in three different primary cultures of mesothelial cells (representative results are reported in Table 1).

Consistent with their classification as melanocyte differentiation antigens, no expression of Melan-A/MART-1 and tyrosinase was detected in mesothelial and MM cells (data not shown).

\section{Induction and up-regulation of CTA expression by 5-AZA-CdR in MM cells}

In order to determine whether DNA methylation could account for the heterogeneous expression of CTA in MM, RT - PCR analysis of CTA expression was performed on total RNA from MPP-89, MESMM98, MES-OC99, MES-1, and MES-2 MM cells, treated with the DNA hypomethylating agent 5-AZA-CdR and compared with untreated controls. Treatment with 5-AZA-CdR consistently induced the expression of MAGE-1, $-2,-3$ and -4 , NY-ESO-1, and SSX-2 in MM cells constitutively negative for one or more of these CTA (Table 2, Figure 1), with the exception of MAGE-3 in MES-1 MM cells (Table 2). Furthermore, the intensity of RT-PCR products for CTA that were constitutively expressed by MM cells was invariantly higher in 5-AZA-CdR-treated cells (Table 2, Figure 1). Consistently, competitive RT-PCR analysis revealed a six to 10-fold increase in MAGE-3 expression in 5-AZA-CdRtreated MPP-89 and MES-OC99 cells, respectively. As expected, no induction of Melan-A/MART-1 expression was observed following 5-AZA-CdR treatment in MM cells (data not shown).

\section{Biochemical analysis of NY-ESO-1 expressed by 5-AZA-CdR-treated MM cells}

To assess whether the induction/up-regulation of CTA expression observed at mRNA level was followed by the production of the respective protein, immunoprecipitation and Western blotting for NY-ESO-1 were performed on MPP-89 and MES-CM98 MM cells, treated or not with 5-AZA-CdR. 5-AZA-CdR strongly up-regulated the expression of NY-ESO-1 protein in MPP-89 MM cells (Figure 1 ), and induced de novo expression of NY-ESO-1 protein in MESCM98 MM cells (Figure 1). Noteworthy, the molecular weight of NY-ESO-1 expressed by 5-AZA-CdR-treated MPP-89 and MESCM98 MM cells was identical to that of NY-ESO-1 constitutively

Table I RT-PCR analysis of TAA expressed in mesothelial and MM cells

\begin{tabular}{|c|c|c|c|c|c|c|c|}
\hline & \multirow[b]{2}{*}{$\begin{array}{l}\text { Mesothelial } \\
\text { cells }\end{array}$} & \multicolumn{6}{|c|}{ MM cells } \\
\hline & & MPP-89 & $\begin{array}{l}\text { MES- } \\
\text { CM98 }\end{array}$ & $\begin{array}{l}\text { MES- } \\
\text { MM98 }\end{array}$ & $\begin{array}{l}\text { MES- } \\
\text { OC99 }\end{array}$ & MES-I & MES-2 \\
\hline MAGE-I & $-{ }^{\mathrm{a}}$ & + & - & ++ & ++ & + & - \\
\hline MAGE-2 & - & + & + & + & + & - & - \\
\hline MAGE-3 & - & + & ++ & + & + & - & - \\
\hline MAGE-4 & - & - & - & - & - & + & - \\
\hline NY-ESO-I & - & + & - & - & - & - & + \\
\hline GAGE I-2 & - & + & + & + & + & + & + \\
\hline GAGE I-6 & - & + & + & ++ & + & + & + \\
\hline SSX 2 & - & + & - & - & + & + & - \\
\hline SSX I-5 & - & ++ & ++ & ++ & ++ & + & + \\
\hline RAGE-I & ++ & ++ & - & ++ & + & + & - \\
\hline$\beta$-actin & ++ & ++ & ++ & ++ & ++ & ++ & ++ \\
\hline
\end{tabular}

antensity of RT-PCR products: - , not detectable; + , weak; ++ , strong. 
Table 2 RT-PCR analysis of TAA expressed by 5-AZA-CdR-treated MM cells

\begin{tabular}{|c|c|c|c|c|c|c|c|c|c|c|}
\hline & \multicolumn{2}{|c|}{ MPP-89 } & \multicolumn{2}{|c|}{ MES-MM98 } & \multicolumn{2}{|c|}{ MES-OC99 } & \multicolumn{2}{|r|}{ MES-I } & \multicolumn{2}{|r|}{ MES-2 } \\
\hline & Ctrl & 5-AZA-CdR & Ctrl & 5-AZA-CdR & Ctrl & 5-AZA-CdR & Ctrl & 5-AZA-CdR & Ctrl & 5-AZA-CdR \\
\hline MAGE-I & $+^{\mathrm{a}}$ & ++ & ++ & ++ & ++ & ++ & + & ++ & - & + \\
\hline MAGE-2 & + & ++ & + & ++ & + & ++ & - & ++ & - & + \\
\hline MAGE-3 & + & ++ & + & ++ & + & ++ & - & - & - & + \\
\hline MAGE-4 & - & ++ & - & ++ & - & ++ & + & ++ & - & ++ \\
\hline NY-ESO-I & + & ++ & - & ++ & - & ++ & - & ++ & + & ++ \\
\hline GAGEI-2 & + & ++ & + & ++ & + & ++ & + & ++ & + & ++ \\
\hline GAGEI-6 & + & ++ & ++ & ++ & + & ++ & + & ++ & + & ++ \\
\hline SSX 2 & + & ++ & - & + & + & ++ & + & ++ & - & ++ \\
\hline RAGE-I & ++ & ++ & ++ & ++ & + & + & + & + & - & - \\
\hline$\beta$-actin & ++ & ++ & ++ & ++ & ++ & ++ & ++ & ++ & ++ & ++ \\
\hline
\end{tabular}

antensity of RT-PCR products: - , not detectable; + , weak; ++ , strong.

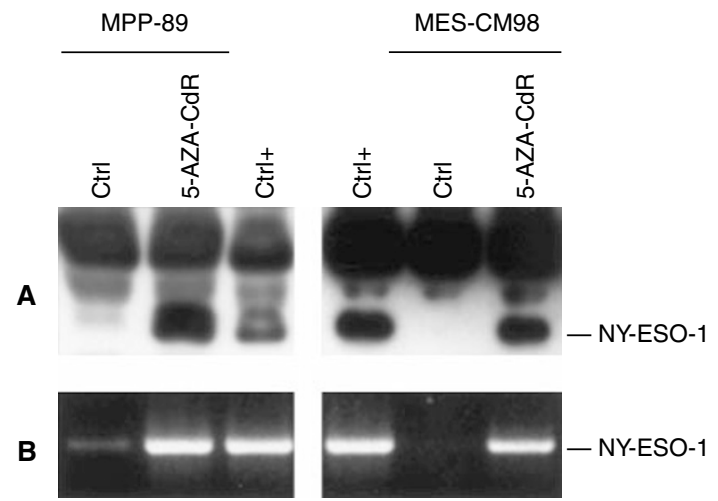

Figure I Expression of NY-ESO-I in 5-AZA-CdR-treated MM cells. (A) Cell lysates of MPP-89 and MES-CM98 MM cells treated (5-AZA-CdR) or not (Ctrl) with 5-AZA-CdR for $48 \mathrm{~h}$, and of NY-ESO-I-positive fibrosarcoma cells HTI080 (Ctrl+), were immunoprecipitated by an anti-NYESO-I rabbit antiserum, size-fractionated by a I3\% one-dimensional SDS - PAGE under reducing conditions, and blotted onto Hybond-C super transfer nitrocellulose membranes. Then, membranes were incubated with I $\left.\mu \mathrm{g} \mathrm{ml}\right|^{-1}$ of ESI2I anti-NY-ESO-I mAb, and further processed to be developed by the enhanced chemiluminescence technique. (B) Total RNA was extracted from MPP-89 and MES-CM98 MM cells treated (5-AZACdR) or not (Ctrl) with 5-AZA-CdR for $48 \mathrm{~h}$, and from NY-ESO-I-positive fibrosarcoma cells HTI080 (Ctrl+), and RT-PCR was performed using NY-ESO-I-specific primer pair. PCR products were size-fractionated on a $2 \%$ agarose gel and visualised by ethidium bromide staining.

expressed by HT1080 fibrosarcoma cells utilised as positive control (Figure 1).

\section{DISCUSSION}

In this study we demonstrate, for the first time, that different immunogenic CTA are concomitantly but heterogeneously expressed in and among human MM specimens. CTA belonging to the MAGE, GAGE and SSX gene families were highly expressed in MM cells analysed (Table 1). This pattern of CTA expression in MM is consistent with the elevated frequency of MAGE family gene expression reported in metastatic melanomas (Brasseur et al, 1995); indeed, five out of six MM cells examined expressed MAGE-1 and/or -2, and/or -3 genes (Table 1). Noteworthy, MAGE-3 was highly expressed by MM cells; this finding suggests that MAGE-3, an extensively utilised therapeutic target for cancer immunotherapy (Marchand et al, 1999; Nishiyama et al, 2001), represents a promising candidate for CTAbased immunotherapy in the majority of MM patients.

Interestingly, the MM cells analysed concomitantly expressed at least four CTA (Table 1), suggesting for the possibility to vaccinate
MM patients against multiple therapeutic CTA. Such an approach may serve to reduce the emergence of CTA-negative clones that may escape treatment-induced immune recognition of MM cells. However, the constitutive intratumour heterogeneity of CTA utilised as therapeutic targets (dos Santos et al, 2000) could also impair the clinical outcome of CTA-specific immunotherapeutic approaches, through the emergence of CTA-negative neoplastic clones. In this respect, the ability of 5-AZA-CdR to demethylate genomic DNA (Razin and Riggs, 1980), resulting in the induction or up-regulation of different CTA (Table 2, Figure 1), suggests that its in vivo administration might revert the CTA-negative phenotype of intratumour MM clones. The feasibility of this approach is further supported by recent evidences indicating that CTA expression induced by 5-AZA-CdR in melanoma cells is long-lasting (Coral et al, 1999; De Smet et al, 1999), remaining stable throughout cellular replication (De Smet et al, 1999).

We also found that 5-AZA-CdR up-regulates the expression of HLA class I antigens, and of the co-stimulatory molecules intercellular adhesion molecule-1 and leukocyte function-associated antigen-3 on MES-MM98 MM cells (data not shown). Thus, in vivo administration of 5-AZA-CdR, in addition to induce/up-regulate CTA expression by MM cells, might also enhance their constitutive immunogenicity through the up-regulated expression of distinct components recognised on transformed cells by $\mathrm{T}$ lymphocytes.

Due to its suggested immunotherapeutic potential (Gaugler et al, 1996; Neumann et al, 1998), the distribution of the TAA RAGE-1 was also investigated. Noteworthy, RAGE-1 was expressed in all benign and malignant mesothelial cells investigated, with the exception of MES-CM98 and MES-2 MM cells (Table 1). This pattern of RAGE-1 expression represents a unique feature of mesothelial and mesothelioma cells; in fact, RAGE-1 is rarely expressed in solid malignancies, and only in the retina among normal tissues (Gaugler et al, 1996). The distribution of RAGE-1 in benign and malignant mesothelial cells closely resembles that of melanocyte differentiation antigens in melanoma (Traversari, 1999), and suggests for a possible tissue-specificity of RAGE-1 expression.

The results of this study, although preliminary, strongly suggest that CTA-based immunotherapy may represent a suitable therapeutic approach to $\mathrm{MM}$, and provide the scientific background for new and eventually more effective chemo-immunotherapeutic approaches in MM patients.

\section{ACKNOWLEDGEMENTS}

Supported in part by the Associazione Italiana per la Ricerca sul Cancro (M Maio and M Tognon), the CNR Target Project Biotechnology (M Tognon) and by the Progetto Ricerca Finalizzata awarded by the Italian Ministry of Public Health (M Maio). 


\section{REFERENCES}

Brasseur F, Rimoldi D, Liénard D, Lethé B, Carrel S, Arienti F, Suter L, Vanwjick R, Bourlond A, Humblet Y, Vacca A, Conese M, Lahaye T, Degiovanni G, Deraemaecker R, Beauduin M, Sastre X, Salamon E, Dreno B, Jäger E, Knuth A, Chevreau C, Suciu S, Lachapelle J-M, Pouillart P, Parmiani G, Lejeune F, Cerottini J-C, Boon T, Marchand M (1995) Expression of MAGE genes in primary and metastatic cutaneous melanoma. Int $\mathrm{J}$ Cancer 63: $375-380$

Caminschi I, Venetsanakos E, Leong CC, Garlepp MJ, Scott B, Robinson BW (1998) Interleukin-12 induces an effective antitumor response in malignant mesothelioma. Am J Respir Cell Mol Biol 19: 738-746

Castagneto B, Zai S, Mutti L, Lazzaro A, Ridolfi R, Piccolini E, Ardizzoni A, Fumagalli L, Valsuani G, Botta M (2001) Palliative and therapeutic activity of IL-2 immunotherapy in unresectable malignant pleural mesothelioma with pleural effusion: Results of a phase II study on 31 consecutive patients. Lung Cancer 31: 303-310

Coral S, Sigalotti L, Gasparollo A, Cattarossi I, Visintin A, Cattelan A, Altomonte M, Maio M (1999) Prolonged upregulation of the expression of HLA class I antigens and costimulatory molecules on melanoma cells treated with 5-aza-2'-deoxycytidine (5-AZA-CdR). J Immunother 22: 16-24

De Smet C, De Backer O, Faraoni I, Lurquin C, Brasseur F, Boon T (1996) The activation of human gene MAGE-1 in tumor cells is correlated with genome-wide demethylation. Proc Natl Acad Sci USA 93: 7149-7153

De Smet C, Lurquin C, Lethe B, Martelange V, Boon T (1999) DNA methylation is the primary silencing mechanism for a set of germ line- and tumorspecific genes with a CpG-rich promoter. Mol Cell Biol 19: 7327-7335

dos Santos NR, Torensma R, de Vries TJ, Schreurs MWJ, de Bruijn DRH, Kater-Baats E, Ruiter DJ, Adema GJ, van Muijen GNP, van Kessel AG (2000) Heterogeneous expression of the SSX cancer/testis antigens in human melanoma lesions and cell lines. Cancer Res 60: 1654-1662

Gaugler B, Brouwenstijn N, Vantomme V, Szikora JP, Van der Spek CW, Patard JJ, Boon T, Schrier P, Van den Eynde BJ (1996) A new gene coding for an antigen recognized by autologous cytolytic $\mathrm{T}$ lymphocytes on a human renal carcinoma. Immunogenetics 44: 323-330

Jäger E, Chen Y-T, Drijfhout JW, Karbach J, Ringhoffer M, Jäger D, Arand M, Wada H, Noguchi Y, Stockert E (1998) Simultaneous humoral and cellular immune response against cancer-testis antigen NY-ESO-1: Definition of human histocompatibility leukocyte antigen (HLA)-A2-binding peptide epitopes. J Exp Med 187: 265-270

Jones PA, Takai D (2001) The role of DNA methylation in mammalian epigenetics. Science 293: $1068-1070$

Jungbluth AA, Chen YT, Stockert E, Busam KJ, Kolb D, Iversen K, Coplan K, Williamson B, Altorki N, Old LJ (2001) Immunohistochemical analysis of NY-ESO-1 antigen expression in normal and malignant human tissues. Int $J$ Cancer 92: 856-860

Lee YC, Light RW, Musk AW (2000) Management of malignant pleural mesothelioma: a critical review. Curr Opin Pulm Med 6: 267-274

Maio M, Altomonte M, Tatake R, Zeff RA, Ferrone S (1991) Reduction in susceptibility to natural killer cell-mediated lysis of human FO-1 melanoma cells after induction of HLA class I antigen expression by transfection with B2m gene. J Clin Invest 88: 282-289
Marchand M, van Baren N, Weynants P, Brichard V, Dréno B, Tessier M-H, Rankin E, Parmiani G, Arienti F, Humblet Y, Bourlond A, Vanwijck R, Liénard D, Beauduin M, Dietrich PY, Russo V, Kerger J, Masucci G, Jäger E, De Greve J, Atzpodien J, Brasseur F, Coulie PG, Van Der BruggenP, Boon T (1999) Tumor regressions observed in patients with metastatic melanoma treated with an antigenic peptide encoded by gene MAGE-3 and presented by HLA-A1. Int J Cancer 80: 219-230

Mutti L, Valle MT, Balbi B, Orengo AM, Lazzaro A, Alciato P, Gatti E, Betta PG, Pozzi E (1998) Primary human mesothelioma cells express class II MHC, ICAM-1 and B7-2 and can present recall antigens to autologous blood lymphocytes. Int J Cancer 78: 740-749

Neumann E, Engelsberg A, Decker J, Storkel S, Jaeger E, Huber C, Seliger B (1998) Heterogeneous expression of the tumor-associated antigens RAGE1, PRAME, and glycoprotein 75 in human renal cell carcinoma: candidates for T-cell-based immunotherapies?. Cancer Res 58: 4090-4095

Nishiyama T, Tachibana M, Horiguchi Y, Nakamura K, Ikeda Y, Takesako K, Murai M (2001) Immunotherapy of bladder cancer using autologous dendritic cells pulsed with human lymphocyte antigen-A24-specific MAGE-3 peptide. Clin Cancer Res 7: 23-31

Razin A, Riggs AD (1980) DNA methylation and gene function. Science 210: $604-610$

Robinson C, Robinson BW, Lake RA (1998) Sera from patients with malignant mesothelioma can contain autoantibodies. Lung Cancer 20: 175184Robinson C, Robinson BW, Lake RA (1998) Sera from patients with malignant mesothelioma can contain autoantibodies. Lung Cancer 20: $175-184$

Sahin U, Koslowski M, Tureci O, Eberle T, Zwick C, Romeike B, Moringlane JR, Schwechheimer K, Feiden W, Pfreundschuh M (2000) Expression of cancer testis genes in human brain tumors. Clin Cancer Res 6: 3916-3922

Sigalotti L, Coral S, Nardi G, Spessotto A, Cortini E, Cattarossi I, Colizzi F, Altomonte M, Maio M (2002) Promoter methylation controls the expression of MAGE-2, -3, and -4 genes in human cutaneous. J Immunother 25: $16-26$

Traversari C (1999) Tumor-antigens recognised by T lymphocytes. Minerva Biotecnol 11: 243-253

Van den Eynde B, Peeters O, De Backer O, Gaugler B, Lucas S, Boon T (1995) A new family of genes coding for an antigen recognized by autologous cytolytic T lymphocytes on a human melanoma. J Exp Med 182: 689-698 van Elsas A, van der Minne CE, Borghi M, Van der Spek CW, Braakman E, Osanto S, Schrier PI (1996) CTL recognition of an IL-2 producing human melanoma vaccine. In Immunology of Human Melanoma: Tumor-host Interaction and Immunotherapy, Maio M (ed) pp 165-173. Amsterdam, Oxford, Tokyo, Washington DC: Ios Press 